\title{
Typing Clostridium difficile strains based on tandem repeat
} sequences

\author{
N Henning Zaiß1, Maja Rupnik2,3, Ed J Kuijper ${ }^{4}$, Celine Harmanus ${ }^{4}$, \\ Dolf Michielsen $^{5}$, Koen Janssens ${ }^{5}$ and Ulrich Nübel ${ }^{* 1}$
}

\begin{abstract}
Address: ${ }^{1}$ Robert Koch Institute, Wernigerode, Germany, ${ }^{2}$ University of Maribor, Maribor, Slovenia, ${ }^{3}$ Institute of Public Health Maribor, Maribor, Slovenia, ${ }^{4}$ Department of Medical Microbiology, Center of Infectious Diseases, Leiden University Medical Center, Leiden, The Netherlands and ${ }^{5}$ Applied Maths NV, Sint-Martens-Latem, Belgium

Email: N Henning Zaiß - zaissn@rki.de; Maja Rupnik - maja.rupnik@uni-mb.si; Ed J Kuijper - E.J.Kuijper@lumc.nl; Celine Harmanus - c.harmanus@lumc.nl; Dolf Michielsen - dolf_michielsen@applied-maths.com; Koen Janssens - koen_janssens@appliedmaths.com; Ulrich Nübel* - nuebelu@rki.de

* Corresponding author
\end{abstract}

Published: 8 January 2009

BMC Microbiology 2009, 9:6 doi:10.1186/147|-2/80-9-6
Received: 2 October 2008

Accepted: 8 January 2009

This article is available from: http://www.biomedcentral.com/I47I-2/80/9/6

(C) 2009 Zaiß et al; licensee BioMed Central Ltd.

This is an Open Access article distributed under the terms of the Creative Commons Attribution License (http://creativecommons.org/licenses/by/2.0), which permits unrestricted use, distribution, and reproduction in any medium, provided the original work is properly cited.

\begin{abstract}
Background: Genotyping of epidemic Clostridium difficile strains is necessary to track their emergence and spread. Portability of genotyping data is desirable to facilitate inter-laboratory comparisons and epidemiological studies.

Results: This report presents results from a systematic screen for variation in repetitive DNA in the genome of $C$. difficile. We describe two tandem repeat loci, designated 'TR6' and 'TR I0', which display extensive sequence variation that may be useful for sequence-based strain typing. Based on an investigation of $154 \mathrm{C}$. difficile isolates comprising 75 ribotypes, tandem repeat sequencing demonstrated excellent concordance with widely used PCR ribotyping and equal discriminatory power. Moreover, tandem repeat sequences enabled the reconstruction of the isolates' largely clonal population structure and evolutionary history.

Conclusion: We conclude that sequence analysis of the two repetitive loci introduced here may be highly useful for routine typing of $C$. difficile. Tandem repeat sequence typing resolves phylogenetic diversity to a level equivalent to PCR ribotypes. DNA sequences may be stored in databases accessible over the internet, obviating the need for the exchange of reference strains.
\end{abstract}

\section{Background}

Clostridium difficile is a Gram-positive, spore-forming, obligately anaerobic bacterium. It is the leading cause of nosocomial diarrhoea among patients undergoing antibiotic treatment $[1,2]$. The severity of $C$. difficile-associated disease (CDAD) ranges from mild diarrhoea to pseudomembranous colitis, toxic megacolon, and intestinal perforation [3-6]. Mortality rates of CDAD reportedly range from 6 to $30 \%[5,7,8]$. During the last decade, the incidence of CDAD has increased significantly in North America [9-12] and Europe [4,8,13,14]. In the USA and Canada, this increase has been associated with the emergence of a novel, hypervirulent strain designated NAP1/ $027[11,15]$. Strains with the same genotype and associated outbreaks have also been reported from several European countries [14,16-18]. 
For infection control investigations and epidemiological studies, it is mandatory to track the emergence and spread of epidemic strains. For this purpose, appropriate genotyping methods are needed. The utility of a typing method will depend on its inter-laboratory reproducibility and data portability, its discriminatory power and concordance of identified groupings with epidemiology, the temporal stability of the genetic markers investigated, and the universal typeability of isolates [19]. Multilocus variable number of tandem repeats analysis (MLVA) is the most discriminatory method presently available for typing $C$. difficile $[20,21]$. Recently reported results suggested that the level of resolution achieved through MLVA may be highly useful for detecting epidemiological clusters of CDAD within and between hospitals $[21,22]$. The genetic loci currently exploited for MLVA-typing of $C$. difficile accumulate variation so rapidly, however, that longerterm relationships between isolates get obscured [23]. It is therefore advisable - and has been a common practice to combine MLVA with the analysis of more conserved genetic markers [20-23]. Most commonly applied approaches to genotyping $C$. difficile at present are DNA macrorestriction analysis (based on pulsed-field gel electrophoresis, mostly used in Canada and the USA $[12,15,24]$ ) and PCR ribotyping (in Europe [25-27]). These two methods yield largely concordant results $[23,27]$. While DNA macrorestriction has slightly higher discriminatory power than PCR ribotyping, it is also more labour-intensive and time consuming [23,27-29].

A major disadvantage of PCR ribotyping, DNA macrorestriction, and other band-based typing techniques (including restriction endonuclease analysis (REA) [30]) is the poor portability and interlaboratory comparability of the generated data. Bacterial strains to be compared usually need to be run on the same electrophoresis gels, which requires the exchange of reference strains between institutions. This requirement seriously hampers epidemiological investigations, particularly at international scales $[21,23]$.

Typing procedures based on DNA sequences overcome these limitations, since sequence data may easily be exchanged and stored in databases that are accessible via the internet. Accordingly, a scheme for multilocus sequence typing (MLST) of C. difficile was developed recently that is based on sequences from seven housekeeping gene fragments [31]. While MLST to date has been applied to a limited number of isolates, available data allowed a first glimpse at the largely clonal genetic population structure of $C$. difficile $[23,31,32]$. In clonal bacteria, novel genotypes in the course of evolution are generated primarily through mutations, which in slowly evolving housekeeping genes are rare. Hence, it is this very clonality of $C$. difficile and the associated linkage disequi- librium that causes MLST to provide poor discriminatory power, which is exemplified by the fact that relevant epidemic strains are not resolved [31]. In addition, MLST remains too expensive to be applied for routine typing aside from dedicated research projects.

More variable genomic regions may provide improved discrimination ability. In contrast to MLST, it may even suffice to sequence a single locus or very few genetic loci that are sufficiently variable, since - analysing a clonal population - phylogenetic inferences will rarely be confounded through homologous genetic recombination. Sequence-based typing schemes relying on one or several highly discriminatory markers have previously been established for a number of pathogens, including Staphylococcus aureus (spa gene) [33], Campylobacter jejuni (flaA) [34,35], Streptococcus pyogenes (emm) [36] and Neisseria meningitidis (porA, fetA) [37-39].

The surface layer protein gene slpA has recently been proposed as a promising target for sequence-based typing of C. difficile [40]. The limited data available suggests extremely high sequence variation among isolates and, correspondingly, excellent discriminatory power $[23,40]$. To date, however, slpA sequencing reportedly has been applied to a total of only 11 different ribotypes, and it is not clear if the method is universally applicable $[23,40]$. It is anticipated that the requirement for degenerate oligonucleotide primers may restrict the general utility of the current protocol [39]. The method has as yet not been successfully transferred to any other laboratory $[23,40]$.

This present report describes the development and application of a new assay for genotyping $C$. difficile that is based on sequence analysis of two stretches of repetitive DNA. Investigating a panel of 154 diverse C. difficile isolates, we demonstrate extensive sequence variation in these genomic regions, resulting in high discriminatory power, and excellent concordance with PCR ribotyping.

\section{Results and discussion Identification of tandem repeat regions suitable for sequence-based typing}

A total of 49 tandem repeat regions that met the selection criteria (repeat size, 15-40 bp; repeat copy number, $>5$; consensus sequence match, $<90 \%$ ) were detected in the genome sequence from strain 630 by using the program Tandem Repeats Finder version $4.00[41,42]$. For 36 of these repeat regions, it was possible to design PCR primers targeting flanking sequences, and from 28, PCR amplification products could reliably be generated from a panel of reference isolates. However, at 25 of these loci, sequence variation was insufficient to discriminate widely distributed strains, including ribotypes 027, 017, and 001 (not shown). The remaining three repeat regions could dis- 
criminate most of the ribotypes examined. The two most variable loci were designated TR6 and TR10 (Table 1). They are located at positions $0.7 \mathrm{Mb}$ and $3.7 \mathrm{Mb}$ of the $C$. difficile 630 chromosome, respectively, and exhibited both, sequence and length polymorphisms. Locus TR6 is composed of 21-basepair repeat units and resides within an open reading frame encoding a hypothetical protein (orf CD0603 in the 630 genome sequence). A homology search in public databases did not identify any significant similarities with known proteins. In contrast, TR10 is located within a predicted non-coding region. It consists of 22-basepair repeats.

We developed a DNA based typing scheme for C. difficile based on the sequence variation of TR6 and TR10. To facilitate the application of the tandem repeat sequence typing (TRST) scheme, a duplex PCR was designed which allowed simultaneous amplification of both loci (Figure 1). Sequence data were generated from duplex PCR products using the same primers as for amplification. Nucleotide sequences from TR6 and TR10 were concatenated and unique repeat successions were assigned distinct TRST types (tagged with consecutive numbers, prefixed with "tr"; Figure 2, Additional files 1, 2). A detailed comparison of TRST with PCR ribotyping is described in the following.

\section{Clonal evolution of tandem repeat regions}

Genomic regions with short tandem repeat regions may evolve fast due to intra-molecular recombination and frequent polymerase slippage during DNA replication [4345]. Accordingly, loci TR6 and TR10 displayed both, sequence polymorphisms, generated through exchange of individual nucleobases (Additional files 3, 4), and length polymorphisms, as a consequence of repeat copy number variation (Additional file 2). Sequences of individual repeats were highly variable, with a nucleotide diversity $\pi$ of $0.28 \pm 0.01$ for TR6 and $0.23 \pm 0.01$ for TR10. The majority of nucleotide substitutions at locus TR6 were synonymous, i. e., they left the encoded amino acid sequence unaffected, and hence may be considered selectively neutral. This was reflected by a $K a / K s$ value of 0.39 , suggesting TR6 sequences evolve under purifying selection. Locus TR10 does not encode any protein and, hence, sequence variation likely is neutral, too.
Furthermore, there is evidence of rare recombination between chromosomes from different strains, affecting tandem repeat sequences. One homologous recombination event apparently generated TRST type tr-021. While tr-021 shares an identical TR6 sequence with tr-011 (Additional file 2), its TR10 allele differs profoundly from that of tr-011 in both, length and sequence (Additional files 4 and 2), even though isolates displaying tr-011 (isolate N551) and tr-021 (SMI037) are affiliated to the same MLST type (ST-39) and ribotype (011; Figure 3). Interestingly, the TR10 allele of tr-021 is identical to the one of tr005 (Additional file 2). Hence, the drastic difference between central parts of TR10 in tr-011 and tr-021 may be explained through a single event of horizontal gene transfer from an unrelated strain. Very similarly, tr-066 and tr045 share identical alleles with closely related TRST types at either TR6 or TR10, respectively, yet differ drastically along a contiguous stretch of central repeats at the other tandem repeat locus. Again, identical alleles may be found elsewhere in the database (Additional file 2), suggesting they were horizontally transferred. In our dataset, these three TRST types displayed the only such discrepancies. We conclude that genetic recombination between unrelated chromosomes was involved in the evolution of maximally three TRST types out of 72 that were included in our set of isolates. Hence, the evolution of tandem repeats TR6 and TR10 is driven largely through clonal diversification, whereas the impact of recombination is extremely small. These results fully corroborate a previous estimate of a very low recombination rate in $C$. difficile, which had been based on MLST data [31].

While TR6 and TR10 displayed remarkable sequence variation, both loci seemed sufficiently stable to identify genetically related isolates collected over time. For one, the stability of TR6 and TR10 was demonstrated by two VPI 10463 and three 630 strains (including the published genome sequence), that prior to our analysis each had been handled in different laboratories (Additional file 1) and, hence, had independently been subcultured multiple times, but yet shared the same respective TRST sequence types (Additional file 1). Furthermore, stability of both tandem repeat regions was circumstantially suggested through identical sequences found in multiple isolates

Table I: Characteristics of tandem repeat loci TR6 and TRI0.

\begin{tabular}{llllll}
\hline tandem repeat locus & Location $^{\mathbf{a}}$ & Size (bp) & Copy no. Range & $\begin{array}{l}\text { No. of different } \\
\text { repeats }\end{array}$ & Repeat consensus $^{\mathbf{b}}$ \\
\hline TR6 & $725321: 725600$ & 21 & $7-37$ & 80 & CTTGCATACCACTAATAGTGC \\
TRI0 & $3753166: 3753574$ & $22-23$ & $4-26$ & 51 & AAATTAATTATTATATTTCTTT \\
\hline
\end{tabular}

a Genome location based on C. difficile 630 sequence http://www.sanger.ac.uk.

b Based on analysis of 154 isolates typed in this study. 


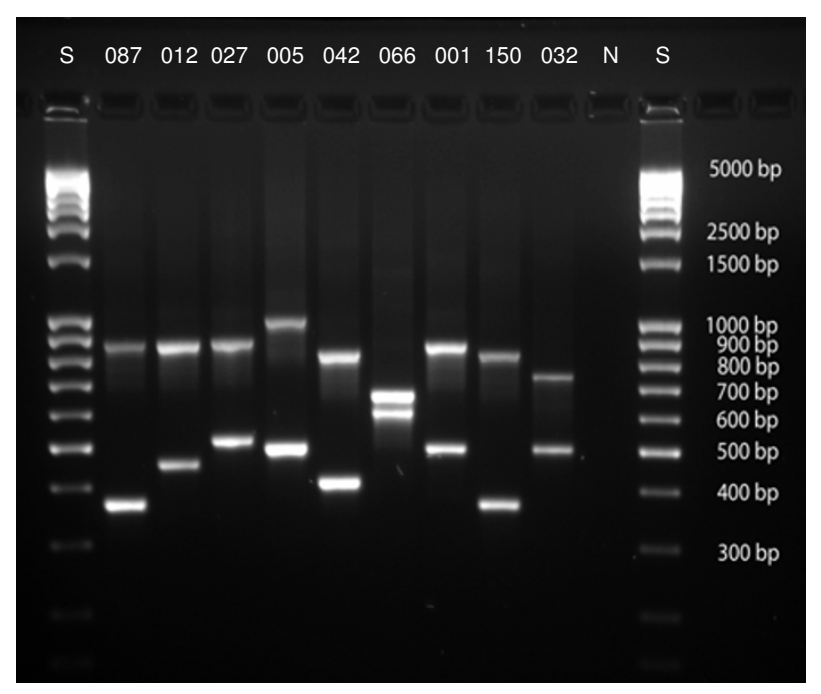

Figure I

Results from duplex PCR amplification of loci TR6 and TRIO, performed on isolates representing various ribotypes as indicated. S, 100 bp DNA ladder; $\mathbf{N}$, negative control; isolates (ribotypes): VPII 0463 (087); 630 (0 I2); NCTC I 3366 (027); TR I 3 (005); N485 (042); SMI055 (066); NCTC I I 204 (00 I); FR535 (I 50); FR505 (032).

sharing the same ribotype but originating from different geographical regions (Additional file 1).

\section{Typeability, discriminatory power, and concordance with $P C R$ ribotyping}

Results were compared to PCR ribotyping on the basis of 154 isolates including international reference strains and clinical isolates collected at various German laboratories (Additional file 1). These isolates had been preselected from the material available to represent maximal diversity as judged on the basis of PCR ribotyping and geographic origin. They represented 75 different ribotypes (Additional file 1). Figure 2 shows a neighbor joining dendrogram based on the repeat successions in concatenated TR6 and TR10 sequences.

All 154 isolates were typeable by TRST. Considering both, differences in length and nucleotide sequence, 43 distinct alleles were identified at locus TR6, and 53 alleles at locus TR10 (Table 2, Additional file 2). Sequencing either one of the two loci had less discriminatory power than PCR ribotyping, as reflected by slightly lower discriminatory indices $(0.93$ and 0.95 , respectively, versus 0.97 for ribotyping; Table 2). When considered in combination, however, sequence analysis of TR6 and TR10 resulted in the identification of 72 different TRST sequence types among the 154 isolates investigated (Additional file 2, Figure 2). This way, TRST and PCR ribotyping had equal discriminatory power, reflected by identical discriminatory indices (Table 2) based on the set of isolates included. It has to be considered, however, that this estimate will be skewed to some extent in favour of ribotyping, since ribotype diversity was the basis of initial isolate selection. Many ribotypes were represented by single isolates, and the potential ability of TRST to further discriminate within these ribotypes was thus not tested.

TRST demonstrated high overall concordance with PCR ribotyping for the set of strains typed in this study, resulting in a calculated Adjusted Rand's index of $89.8 \%$ (Table 2 ). The probability that a pair of isolates with the same ribotype also shared identical TRST sequence types was 89.6\% (Wallace index 0.896). Accordingly, ribotypes usually corresponded to specific TRST sequence types (Figure 2 ). For example, 18 isolates with ribotype 027 , originating from six different European countries, displayed identical sequences at TR6 and TR10 that discriminated them from all other isolates, and jointly were assigned TRST sequence type tr-027 (Additional file 1, Figure 2). Similarly, four isolates with ribotype 017 from three different countries, including the reference strain for toxinotype VIII, were assigned sequence type tr-017 (Additional file 1, Figure 2 ). Future work on larger numbers of isolates may reveal that sequencing a single locus (TR6 or TR10) will suffice to identify epidemiologically relevant strains. For the sake of concordance with PCR ribotyping, however, we presently suggest to sequence both loci. As outlined above, this strategy will also detect the impact of recombination.

\section{Tandem repeat sequences are phylogenetically informative}

Discrepancies between TRST and ribotyping were apparent where either method split a particular group of isolates into two or three classes, whereas the other lumped them into one (Figure 2). In virtually all of these cases, however, the respective isolates were affiliated to identical MLST sequence types or to single locus variants with respect to MLST (i. e., identical sequences at six out of seven MLST loci), indicating their close phylogenetic relatedness. Phylogenetic coherence of these additional (sub)classes will remain unclear as long as there are no phylogenetic markers available to investigate the detailed evolutionary history of $C$. difficile within MLST sequence types.

MLVA typically resolves dozens of distinct genotypes within individual ribotypes $[20,21]$. However, MLVA provided little insight to the genetic relatedness within our collection, since almost all isolates differed from each other at four or more loci [20], even when they were affiliated to identical TRST sequence types or ribotypes (Figure $3)$. The sole useful exception was represented by isolates JW611148 and CL39, which shared identical alleles at five MLVA loci (Figure 3). The summed tandem-repeat differ- 


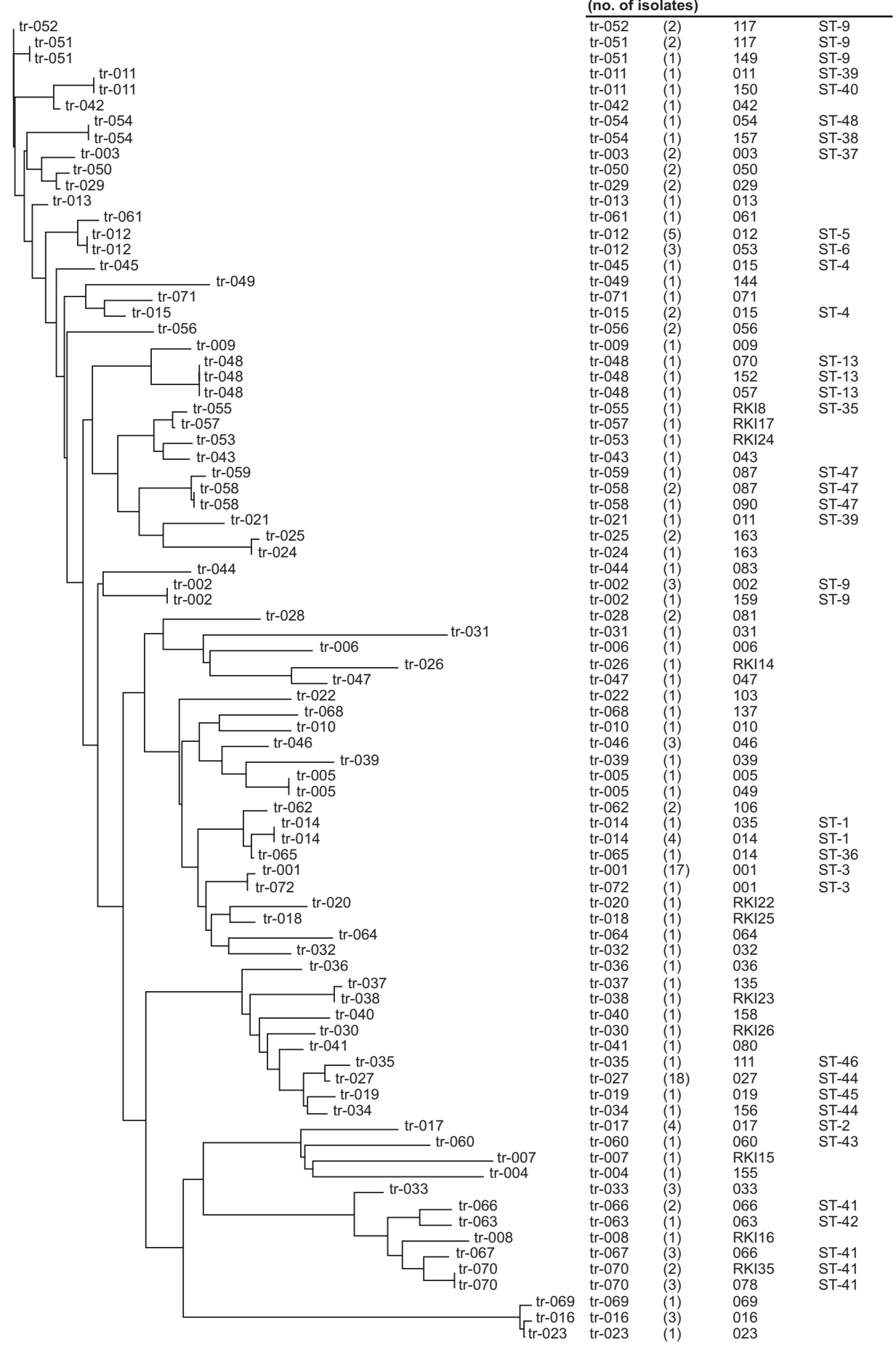

Figure 2

Phylogenetic analysis (neighbor joining) based on the repeat successions in concatenated TR6 and TR I0

sequences from I54 C. difficile isolates. The repeat-distance matrix was calculated based on the DSI model, which considers repeat substitutions, insertions, deletions, and duplications (see Methods; [47]). Corresponding ribotypes, TRST types, and MLST sequence types are indicated. 


\begin{tabular}{|c|c|c|c|c|c|c|c|c|c|c|c|c|c|c|c|c|c|c|c|c|}
\hline $\begin{array}{l}\text { Categorical } \\
\text { MLST } \\
i ণ q\end{array}$ & 8 & $\infty$ & Isolate & MLST type & $\begin{array}{l}\frac{\omega}{0} \\
\frac{0}{5} \\
\frac{5}{0} \\
\stackrel{5}{\Sigma}\end{array}$ & $\begin{array}{l}\bar{z} \\
\overline{0} \\
\frac{1}{5} \\
\stackrel{\vec{\Sigma}}{\Sigma}\end{array}$ & $\begin{array}{l}\frac{5}{3} \\
\frac{1}{1} \\
\frac{1}{\Delta}\end{array}$ & $\begin{array}{l}\text { 音 } \\
\frac{1}{\omega} \\
\stackrel{\omega}{\Sigma}\end{array}$ & 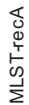 & $\begin{array}{l}\frac{1}{0} \\
0 \\
\frac{p}{5} \\
\frac{5}{2} \\
\Sigma\end{array}$ & 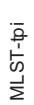 & Ribotype & TRST type & $\begin{array}{l}\frac{0}{4} \\
+ \\
\dot{1} \\
\Sigma\end{array}$ & 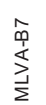 & 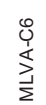 & $\frac{\widehat{\psi}}{\frac{W}{\Sigma}}$ & 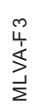 & & , \\
\hline & & & SMI055 & ST-41 & 7 & 0 & 4 & 6 & 7 & 9 & 5 & 066 & tr-067 & 0 & 16 & 25 & 6 & 5 & 14 & \\
\hline & & & SE881 V & ST-41 & 7 & 0 & 4 & 6 & 7 & 9 & 5 & 066 & $\operatorname{tr}-066$ & 0 & 29 & 25 & 6 & 5 & 13 & \\
\hline & & & R114 & ST-41 & 7 & 0 & 4 & 6 & 7 & 9 & 5 & 066 & $\operatorname{tr}-067$ & 0 & 19 & 34 & 5 & 5 & 20 & \\
\hline & & & CL39 & ST-41 & 7 & 0 & 4 & 6 & 7 & 9 & 5 & RKI35 & $\operatorname{tr}-070$ & 0 & 19 & 31 & 8 & 5 & 12 & \\
\hline & & & JW611148 & ST-41 & 7 & 0 & 4 & 6 & 7 & 9 & 5 & 078 & $\operatorname{tr}-070$ & 0 & 17 & 29 & 8 & 5 & 12 & \\
\hline & & & 57267 VII & ST-42 & 12 & 0 & 4 & 8 & 7 & 8 & 2 & 063 & tr-063 & 0 & 21 & 27 & 10 & 5 & 15 & \\
\hline & & & CL43 & ST-2 & 4 & 0 & 3 & 3 & 3 & 4 & 3 & 017 & $\operatorname{tr}-017$ & 3 & 9 & 23 & 8 & 6 & 37 & \\
\hline & & & ATCC43593 & ST-43 & 4 & 0 & 3 & 3 & 3 & 5 & 8 & 060 & $\operatorname{tr}-060$ & 31 & 21 & 39 & 8 & 6 & 23 & \\
\hline & & & SMI003 & ST-9 & 5 & 4 & 2 & 2 & 1 & 1 & 1 & 002 & tr-002 & 18 & 17 & 24 & 6 & 6 & 7 & \\
\hline & & & CL46 & ST-9 & 5 & 4 & 2 & 2 & 1 & 1 & 1 & 117 & $\operatorname{tr}-051$ & 32 & 18 & 42 & 11 & 5 & 11 & \\
\hline & & & FR236 & ST-9 & 5 & 4 & 2 & 2 & 1 & 1 & 1 & 149 & tr-051 & 26 & 19 & 27 & 9 & 5 & 13 & \\
\hline & & & FR650 & ST-9 & 5 & 4 & 2 & 2 & 1 & 1 & 1 & 159 & tr-002 & 28 & 12 & 26 & 7 & 6 & 10 & \\
\hline & & & SMI025 & ST-37 & 3 & 4 & 2 & 2 & 2 & 1 & 1 & 003 & tr-003 & 35 & 11 & 18 & 11 & 5 & 3 & \\
\hline & & & CL45 & ST-13 & 3 & 1 & 2 & 2 & 1 & 3 & 1 & 070 & $\operatorname{tr}-048$ & 22 & 15 & 32 & 6 & 6 & 7 & \\
\hline & & & FR342 & ST-13 & 3 & 1 & 2 & 2 & 1 & 3 & 1 & 152 & $\operatorname{tr}-048$ & 33 & 9 & 27 & 5 & 6 & 8 & \\
\hline & & & FR615 & ST-13 & 3 & 1 & 2 & 2 & 1 & 3 & 1 & 057 & $\operatorname{tr}-048$ & 17 & 8 & 29 & 6 & 6 & 9 & \\
\hline & & & FR182 & ST-48 & 5 & 2 & 1 & 1 & 1 & 1 & 9 & 054 & tr-054 & 32 & 9 & 26 & 4 & 6 & 8 & \\
\hline & & & FR548 & ST-38 & 5 & 2 & 1 & 1 & 1 & 1 & 1 & 157 & tr-054 & 48 & 14 & 39 & 8 & 6 & 4 & \\
\hline & & & SMI037 & ST-39 & 3 & 4 & 1 & 1 & 1 & 1 & 1 & 011 & $\operatorname{tr}-021$ & 30 & 20 & 27 & 9 & 6 & 7 & \\
\hline & & & N551 & ST-39 & 3 & 4 & 1 & 1 & 1 & 1 & 1 & 011 & $\operatorname{tr}-011$ & 26 & 4 & 34 & 10 & 6 & 6 & \\
\hline & & & FR535 & ST-40 & 3 & 1 & 1 & 1 & 1 & 1 & 1 & 150 & $\operatorname{tr}-011$ & 33 & 24 & 29 & 8 & 6 & 10 & \\
\hline & & & NCTC 13366 & ST-44 & 13 & 4 & 5 & 1 & 1 & 2 & 1 & 027 & $\operatorname{tr}-027$ & 35 & 17 & 44 & 10 & 5 & 16 & \\
\hline & & & T-378 & ST-44 & 13 & 4 & 5 & 1 & 1 & 2 & 1 & 027 & $\operatorname{tr}-027$ & 30 & 15 & 31 & 8 & 5 & 13 & \\
\hline & & & JW608204 & ST-44 & 13 & 4 & 5 & 1 & 1 & 2 & 1 & 027 & $\operatorname{tr}-027$ & 25 & 8 & 33 & 10 & 5 & 16 & \\
\hline & & & FR529 & ST-44 & 13 & 4 & 5 & 1 & 1 & 2 & 1 & 156 & $\operatorname{tr}-034$ & 24 & 18 & 36 & 6 & 5 & 10 & \\
\hline & & & 51680 IX & ST-45 & 13 & 0 & 5 & 1 & 1 & 2 & 1 & 019 & tr-019 & 33 & 14 & 32 & 4 & 6 & 11 & \\
\hline & & & $\mathrm{CH} 6230 \mathrm{IIIC}$ & ST-46 & 11 & 0 & 2 & 1 & 1 & 2 & 1 & 111 & $\operatorname{tr}-035$ & 29 & 26 & 19 & 6 & 5 & 25 & \\
\hline & & & VPI 10463 & ST-47 & 14 & 4 & 2 & 1 & 1 & 10 & 1 & 087 & tr-058 & 27 & 8 & 36 & 5 & 6 & 11 & \\
\hline & & & P5732 & ST-47 & 14 & 4 & 2 & 1 & 1 & 10 & 1 & 087 & $\operatorname{tr}-059$ & 35 & 10 & 21 & 6 & 6 & 11 & \\
\hline & & & FR434 & ST-47 & 14 & 4 & 2 & 1 & 1 & 10 & 1 & 090 & tr-058 & 24 & 14 & 45 & 7 & 6 & 8 & \\
\hline & & & JW609048 & ST-1 & 2 & 2 & 2 & 1 & 2 & 2 & 1 & 014 & tr-014 & 29 & 10 & 42 & 5 & 5 & 8 & \\
\hline & & & FR413 & ST-1 & 2 & 2 & 2 & 1 & 2 & 2 & 1 & 035 & $\operatorname{tr}-014$ & 31 & 22 & 27 & 6 & 5 & 7 & \\
\hline & & & AB454 & ST-4 & 5 & 2 & 2 & 1 & 1 & 2 & 1 & 015 & $\operatorname{tr}-045$ & 47 & 21 & 32 & 3 & 6 & 10 & \\
\hline & & & R5 & ST-4 & 5 & 2 & 2 & 1 & 1 & 2 & 1 & 015 & $\operatorname{tr}-015$ & 39 & 16 & 37 & 3 & 6 & 12 & \\
\hline & & & NCTC 11204 & ST-3 & 2 & 2 & 2 & 1 & 1 & 5 & 1 & 001 & tr-001 & 26 & 21 & 21 & 6 & 6 & 11 & \\
\hline & & & AB403 & ST-3 & 2 & 2 & 2 & 1 & 1 & 5 & 1 & 001 & $\operatorname{tr}-001$ & 18 & 15 & 35 & 6 & 6 & 7 & \\
\hline & & & R276 & ST-3 & 2 & 2 & 2 & 1 & 1 & 5 & 1 & 001 & $\operatorname{tr}-072$ & 30 & 7 & 29 & 5 & 6 & 8 & \\
\hline & & & DSMZ 1296 & ST-3 & 2 & 2 & 2 & 1 & 1 & 5 & 1 & 001 & tr-001 & 34 & 9 & 21 & 4 & 6 & 11 & \\
\hline & & & FR549 & ST-3 & 2 & 2 & 2 & 1 & 1 & 5 & 1 & 001 & $\operatorname{tr}-001$ & 33 & 14 & 30 & 5 & 6 & 5 & \\
\hline & & & DSMZ 12056 & ST-35 & 5 & 2 & 2 & 1 & 1 & 5 & 2 & RKI8 & tr-055 & 46 & 16 & 34 & 9 & 3 & 10 & \\
\hline & & & TY4366 & ST-6 & 2 & 2 & 2 & 2 & 1 & 2 & 2 & 053 & $\operatorname{tr}-012$ & 34 & 19 & 38 & 6 & 6 & 15 & \\
\hline & & & 630 & ST-5 & 2 & 2 & 2 & 1 & 1 & 2 & 2 & 012 & $\operatorname{tr}-012$ & 38 & 17 & 17 & 7 & 7 & 6 & \\
\hline & & & SMI007 & ST-36 & 2 & 4 & 2 & 1 & 2 & 1 & 2 & 014 & tr-065 & 27 & 20 & 15 & 4 & 5 & 9 & \\
\hline
\end{tabular}

\section{Figure 3}

Comparison of MLST, PCR ribotyping, TRST and MLVA for 43 C. difficile isolates. Dendrogram is based on UPGMA analysis of MLST allelic profiles.

ence between these two isolates was four repeats, which is below the threshold $(=10)$ previously suggested to indicate close genetic relationship based on MLVA [21]. MLST identity confirmed the relatedness of these isolates (Figure 3 ), and their close phylogenetic relationship also was correctly reflected by identical sequences at TR6 and TR10 (tr- 
Table 2: Discriminatory power and concordance of tandem repeat sequence typing and PCR ribotyping.

\begin{tabular}{|c|c|c|c|c|c|}
\hline Method & No. of strains included & No. of different types & Discriminatory index & $95 \% \mathrm{Cl}$ & $\begin{array}{l}\text { Concordance with } \\
\text { ribotyping (\%) }\end{array}$ \\
\hline PCR ribotyping & 154 & 75 & 0.967 & $0.953-0.982$ & n. a. \\
\hline TRSTb & 154 & 72 & 0.967 & $0.954-0.981$ & 89.8 \\
\hline TR6 sequencing & 154 & 43 & 0.931 & $0.911-0.951$ & 60.4 \\
\hline TRIO sequencing & 154 & 53 & 0.949 & $0.934-0.964$ & 71.6 \\
\hline
\end{tabular}

a Adjusted Rand's coefficient

b Combination of sequences from TR6 and TRI0.

070, Figure 3). However, these isolates displayed a distinct one-band difference between their ribotyping patterns, corresponding to ribotypes 078 and RKI35, respectively (Figure 4). This result illustrates the fact that ribotypes may differ widely with respect to the phylogenetic divergence they encompass. It may be noted that two other pairs of isolates shared highly similar MLVA patterns (AB403/CL45, NCTC11204/P5732; Figure 3). The summed tandem-repeat difference for the former pair is seven repeats, and hence these two isolates would be suggested to be extremely closely related based on MLVA alone [21]. These similarities, however, clearly reflect homoplasies, since MLST indicated these isolates were entirely unrelated (Figure 3). Thus, the application of MLVA as currently used is inappropriate when attempting to resolve distant phylogenetic relationships of $C$. difficile

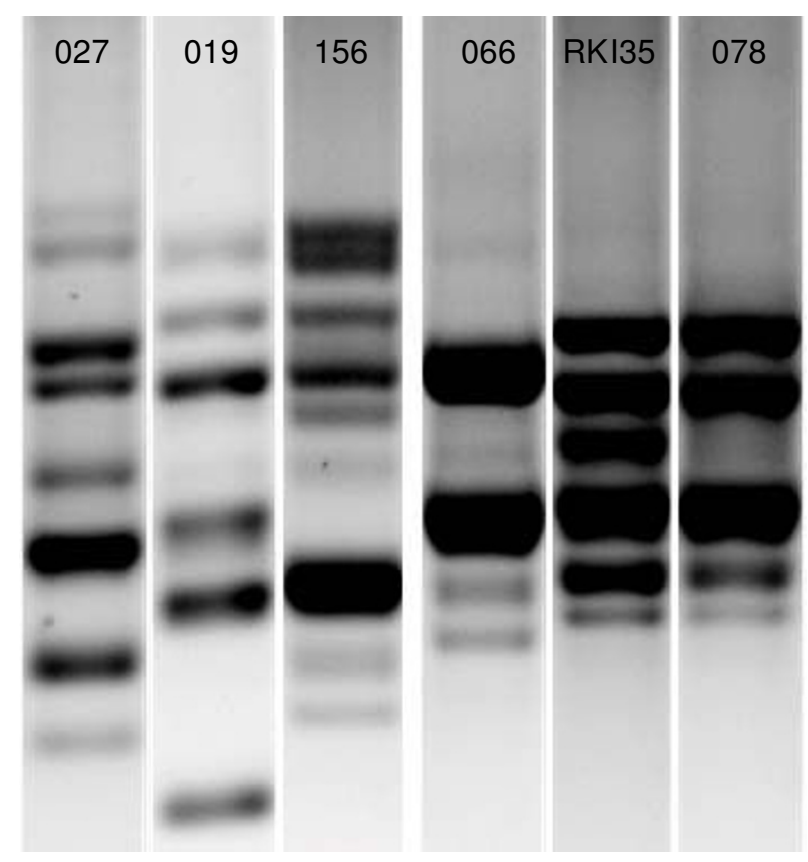

Figure 4

PCR ribotyping band patterns of ribotypes 027 (isolate, NCTC I 3366 ), 0 I 9 (5 I 680), I 56 (FR529), 066 (SE88 I), RKI35 (CL39) and 078 (JW6 I I I 48). isolates. Again, in these cases, phylogeny was correctly indicated by TRST. We therefore conclude that it may be useful to combine TRST and MLVA in a nested hierarchical fashion, where TRST may resolve phylogenetic diversity to a level equivalent to PCR ribotypes, and MLVA may add additional resolution where desired.

Evolutionary relationships between isolates may be revealed through tandem repeat sequence alignment and phylogenetic analysis. This is also feasible for those isolates that were assigned different TRST types. For example, ribotypes 027,156 , and 019 by MLST are indicated to be closely related, since corresponding isolates are assigned two MLST sequence types that differ at one locus only (Figure 3). Close relationship of ribotypes 027 and 019 previously has also been found on the basis of DNA macrorestriction analysis, when isolates with both ribotypes were assigned to the 'North American Pulsotype NAP1' [23]. Concordantly with MLST and macrorestriction, TRST also indicated the relatedness of these types through similar tandem repeat sequences that clustered tightly in the phylogenetic tree (Figure 2), yet it maintained the discriminatory power of PCR ribotyping by assigning three different sequence types (tr-034, tr-027, tr-019) (Figure 2). Similarly, ribotypes 078 and RKI35 were indicated to be closely related to ribotype 066 by both, MLST and TRST (Figures 2 and 3). In contrast, these relationships were not at all apparent on the basis of ribotyping band patterns (Figure 4).

Phylogenetic relatedness was also indicated in cases where TRST was more discriminatory than PCR ribotyping. For example, ribotypes 001, 163, 087, 014, and 117 each were subdivided into several TRST types (Figure 2). Clusters of related tandem repeat sequences in the phylogenetic tree still corresponded to PCR ribotypes (Figure 2), which warrants the comparability of results from both methods. This feature may be highly desirable, since it will facilitate, for example, cross-referencing to ribotyping-based examinations and maintaining the continuity of ongoing surveillance programs.

Ribotyping does not enable phylogenetic analyses based on dissimilar banding patterns, and the relatedness of dif- 
ferent ribotypes has not commonly been assessed. In the long run, large-scale mutation discovery and genomic (re)sequencing will reveal the phylogenetic validity of typing procedures [46].

\section{Future prospects}

We anticipate that PCR ribotyping will eventually be replaced by typing procedure(s) based on DNA sequences. The inherent portability of sequence data will obviate the need for the exchange of reference strains and enable decentralised genotyping efforts, which may boost large scale investigations on the molecular diversity of $C$. difficile. At present, however, our knowledge about the diversity and population biology of this important pathogen is very limited $[23,31,32]$. As a consequence, it is generally not clear if isolate groupings provided by various typing methods, including PCR ribotyping, are concordant with the epidemiology of associated disease [21,23]. Related to these considerations, one limitation of this present study is the lack of epidemiologically linked isolates in our data set. Investigations in the near future should evaluate the utility of tandem repeat sequencing for infection chain tracking and short-term epidemiological investigations.

\section{Conclusion}

Sequence analysis of tandem repeats TR6 and TR10 provided full typeability across a wide range of $C$. difficile isolate diversity, excellent concordance with PCR ribotyping, and equal discriminatory ability. Sequence clades corresponded to phylogenetically coherent groupings. This sequencing-based typing approach may prove particularly useful because DNA sequences can easily be exchanged via the internet.

\section{Methods}

\section{Bacterial isolates}

A total of 154 C. difficile isolates comprising 75 different ribotypes were used in this study. The strain collection included both, international reference strains and selected clinical isolates from various German hospitals, collected in 2007 and 2008. More detailed information about individual isolates is given in Additional file 1.

\section{DNA extraction}

Genomic DNA was isolated from cultures grown for $48 \mathrm{~h}$ on cycloserine-cefoxitin fructose agar (OXOID, Basingstoke, UK), by using the DNeasy Blood \& Tissue Kit (QIAGEN, Hilden, Germany) according to the manufacturer's recommendations.

\section{PCR ribotyping}

PCR ribotyping initially was performed at the Reference Laboratory for Clostridium difficile at the Leiden University Medical Center in the Netherlands and later was trans- ferred to the Robert Koch Institute. We followed the protocol of Bidet et al. [26], except that PCR Products were run on $1.5 \%$ agarose gels in $1 \times$ TBE at 85 volts for 4 hours. Isolates were assigned novel PCR ribotypes if their patterns differed from previously named patterns by at least one band.

\section{Tandem repeat sequence typing (TRST)}

To facilitate the application of tandem repeat sequence typing, a duplex PCR was designed using the following primers: TR6-F (5'-TTTCAACTTGTCCAGTTTTTAAGTC-3') and TR6-R (5'-ATGACATAGCGTTTGTGGAAT-3'); TR10-F (5'-TGCATCAAATTGGTCAAGACTC-3') and TR10-R (5'TGAAATCATTGACTATAAAGCAAAA-3'). DNA amplification was performed on $1 \mu$ l of purified genomic DNA in a final volume of $50 \mu \mathrm{l}$ containing $0.1 \mu \mathrm{M}$ of TR 6 and $1 \mu \mathrm{M}$ of TR10 primers, $200 \mu \mathrm{M}$ of each deoxynucleoside triphosphate, $1 \times$ PeqLab PCR buffer Y $(20 \mathrm{mM}$ Tris-HCL, 16 $\mathrm{mM}\left(\mathrm{NH}_{4}\right)_{2} \mathrm{SO}_{4}, 0.01 \%$ Tween $\left.20,2 \mathrm{mM} \mathrm{MgCl}_{2}\right)$ and 1.25 units Hot Taq-DNA-Polymerase (PeqLab, Erlangen, Germany). After an initial denaturation of $96^{\circ} \mathrm{C}$ for $3 \mathrm{~min}$, the protocol consisted of 35 cycles at $96^{\circ} \mathrm{C}$ for $45 \mathrm{~s}, 52^{\circ} \mathrm{C}$ for $45 \mathrm{~s}$, and $72^{\circ} \mathrm{C}$ for $45 \mathrm{~s}$ following a final extension at $72^{\circ} \mathrm{C}$ for $7 \mathrm{~min}$. PCR products were prepared for sequencing using the QIAquick ${ }^{\circledast}$ PCR Purification Kit (QIAGEN, Hilden, Germany) and $0.35 \mu \mathrm{l}$ of the purified products were applied for sequencing using the BigDye Terminator v3.1 Cycle Sequencing Kit (Applied Biosystems, Foster City, USA) with identical primers employed in the PCR. Automated sequence detection was performed on an ABI capillary sequencing system and sequences were analysed using the BioNumerics 5.10 software (Applied Maths, Belgium).

\section{Classification of TRST types, repeat alignment, and cluster analysis}

Data processing was performed with BioNumerics 5.10 by using a novel, dedicated "Repeat Typing" plugin that allowed automated batch assembly of trace files. The assignment of TRST sequence types was based on the successive occurrence of user-defined repeats in concatenated sequences from both tandem repeat loci. A repeat distance matrix for matching and clustering were calculated based on the DSI model [47], a mutation model comprising substitutions, indels (insertions or deletions), and duplications. Subsequent cluster analysis was performed based on the neighbor joining algorithm.

\section{Multilocus sequence typing}

Clostridium difficile isolates were typed by MLST as described previously [31]. Sequence data were submitted to the C. difficile MLST database http://www.pasteur.fr/ recherche/genopole/PF8/mlst/Cdifficile.html to assign allele profiles and the resulting sequence types. Sequence types were analysed by constructing a dendrogram based 
on the UPGMA (Unweighted Pair Group Method with Arithmetic mean) clustering algorithm using the multistate categorical similarity coefficient (tolerance $0 \%$ ) available in the BioNumerics software.

\section{MLVA}

Seven-locus MLVA was conducted as described previously $[20,22]$, except that the different loci were PCR-amplified individually and PCR products were sequenced for repeat copy number determination. To facilitate sequence analysis of MLVA locus C6 [20], two novel oligonucleotide primers were used: C6-F 5'-CCAAGTCCCAGGATTATTGC3' and C6-R 5'-AACATGGGGATTGGAATTGA-3'. Repeat copy numbers were determined manually using BioNumerics 5.10 software. The summed tandem-repeat difference was calculated where appropriate; it is the sum of repeat differences between two isolates at all seven MLVA loci [21].

\section{Discriminatory power, system concordance and molecular evolutionary analyses}

An index of discrimination was calculated to compare the discriminating capacity of ribotyping, and TRST. The discriminatory index was defined as the average probability of two consecutively sampled strains being characterized as the same type. This probability depends on the number of strain types and their frequency distribution in the population. Discriminatory indices were calculated based on Simpson's index of diversity [48]. Confidence intervals for discriminatory indices were determined as described previously [49]. The Concordance of two typing schemes was calculated based on the adjusted Rand's and Wallace's coefficients [50]. While the Rand's coefficient allows a quantitative evaluation of the global congruence between two typing systems, the Wallace's coefficient compares the congruence of schemes depending on the directionality of typing by estimating the probability that a pair of isolates sharing the same type in system 1 also share the same type in system 2, and vice versa. Calculation of all parameters was performed with EpiCompare software, version 1.0 (Ridom GmbH, Würzburg, Germany).

The nucleotide diversity $(\pi)$ and the ratio $(K a / K s)$ of the average number of non-synonymous substitutions per non-synonymous site $(\mathrm{Ka})$ to the number to synonymous substitutions per synonymous site (Ks) was calculated by using DnaSP, version 4.5 [51].

\section{Authors' contributions}

$\mathrm{HZ}$ and UN designed research. HZ carried out the microbiological and molecular work. MR contributed reagents. DM and KJ devised analysis software. HZ, UN, EK, and $\mathrm{CH}$ performed data analyses. $\mathrm{HZ}, \mathrm{EK}, \mathrm{MR}$, and UN wrote the manuscript.

\section{Additional material}

\section{Additional File 1}

Bacterial isolates. Table providing a list of bacterial isolates (isolate ID, source, geographic origin, PCR ribotype, TRST type, MLST type). Click here for file

[http://www.biomedcentral.com/content/supplementary/14712180-9-6-S1.pdf]

\section{Additional File 2}

TRST types and associated repeat profiles. Table providing TRST types and associated repeat profiles.

Click here for file

[http://www.biomedcentral.com/content/supplementary/1471-

2180-9-6-S2.pdf]

\section{Additional File 3}

Locus TR6, individual repeat sequences identified from 154 isolates. Table providing individual repeat sequences for locus TR6, identified from 154 isolates.

Click here for file

[http://www.biomedcentral.com/content/supplementary/14712180-9-6-S3.pdf]

\section{Additional File 4}

Locus TR10, individual repeat sequences identified from 154 isolates. Table providing individual repeat sequences for locus TR10, identified from 154 isolates.

Click here for file

[http://www.biomedcentral.com/content/supplementary/14712180-9-6-S4.pdf]

\section{Acknowledgements}

We are grateful to all people that have contributed bacterial isolates to this study, particularly to M. Kist, T. Åkerlund, H. Rüssmann, and B. Bornhofen. We thank Wolfgang Witte for inspiring discussions and generous support. For excellent technical assistance we thank Heike Illiger, Annette Weller, and the staff at the sequencing unit of the Robert Koch Institute. This work was partially supported by a grant from the German Federal Ministry of Health.

\section{References}

I. Bartlett JG: Antibiotic-associated pseudomembranous colitis. Rev Infect Dis 1979, I(3):530-539.

2. Thomas C, Stevenson M, Riley TV: Antibiotics and hospitalacquired Clostridium difficile-associated diarrhoea: a systematic review. J Antimicrob Chemother 2003, 5 I (6): I339-I 350.

3. Miller MA, Hyland M, Ofner-Agostini M, Gourdeau M, Ishak M: Morbidity, mortality, and healthcare burden of nosocomial Clostridium difficile-associated diarrhea in Canadian hospitals. Infect Control Hosp Epidemiol 2002, 23(3): 137-140.

4. Kuijper EJ, van Dissel JT, Wilcox MH: Clostridium difficile: changing epidemiology and new treatment options. Curr Opin Infect Dis 2007, 20(4):376-383.

5. Kyne L, Hamel MB, Polavaram R, Kelly CP: Health care costs and mortality associated with nosocomial diarrhea due to Clostridium difficile. Clin Infect Dis 2002, 34(3):346-353.

6. Morgan OW, Rodrigues B, Elston T, Verlander NQ, Brown DF, Brazier J, Reacher M: Clinical severity of Clostridium difficile PCR ribotype 027: a case-case study. PLOS ONE 2008, 3(3):el8II2.

7. Pepin J, Valiquette L, Cossette B: Mortality attributable to nosocomial Clostridium difficile-associated disease during an epi- 
demic caused by a hypervirulent strain in Quebec. Cmaj 2005, I 73(9): 1037-1042.

8. Kuijper EJ, Coignard B, Tull P: Emergence of Clostridium difficile-associated disease in North America and Europe. Clin Microbiol Infect 2006, I2(Suppl 6):2-18.

9. Zilberberg MD, Shorr AF, Kollef MH: Increase in adult Clostridium difficile-related hospitalizations and case-fatality rate, United States, 2000-2005. Emerg Infect Dis 2008, 14(6):929-93 I.

10. McDonald LC, Owings M, Jernigan DB: Clostridium difficile infection in patients discharged from US short-stay hospitals, 1996-2003. Emerg Infect Dis 2006, I2(3):409-4I5.

II. Loo VG, Poirier L, Miller MA, Oughton M, Libman MD, Michaud S, Bourgault AM, Nguyen T, Frenette C, Kelly M, et al.: A predominantly clonal multi-institutional outbreak of Clostridium difficile-associated diarrhea with high morbidity and mortality. N Engl J Med 2005, 353(23):2442-2449.

12. Hubert B, Loo VG, Bourgault AM, Poirier L, Dascal A, Fortin E, Dionne $M$, Lorange $M$ : A portrait of the geographic dissemination of the Clostridium difficile North American pulsed-field type I strain and the epidemiology of C. difficile-associated disease in Quebec. Clin Infect Dis 2007, 44(2):238-244.

13. anonymous: Deaths involving Clostridium difficle: England and Wales, 1999 and 200I-06. Health Stat Q 2008:52-56.

14. Kuijper EJ, Coignard B, Brazier JS, Suetens C, Drudy D, Wiuff C Pituch $\mathrm{H}$, Reichert $\mathrm{P}$, Schneider F, Widmer AF, et al.: Update of Clostridium difficile-associated disease due to $P C R$ ribotype 027 in Europe. Euro Surveill 2007, I 2(6): EI-2.

15. McDonald LC, Killgore GE, Thompson A, Owens RC Jr, Kazakova SV, Sambol SP, Johnson S, Gerding DN: An epidemic, toxin gene-variant strain of Clostridium difficile. N Engl J Med 2005, 353(23):2433-244I.

16. Kuijper EJ, Berg RJ van den, Debast S, Visser CE, Veenendaal D, Troelstra A, Kooi T van der, Hof S van den, Notermans DW: Clostridium difficile ribotype 027 , toxinotype III, the Netherlands. Emerg Infect Dis 2006, I 2(5):827-830.

17. Barbut F, Mastrantonio P, Delmee M, Brazier J, Kuijper E, Poxton I: Prospective study of Clostridium difficile infections in Europe with phenotypic and genotypic characterisation of the isolates. Clin Microbiol Infect 2007, I 3(I I): 1048- 1057.

18. Zaiß NH, Weile J, Ackermann G, Kuijper E, Witte W, Nübel U: A case of Clostridium difficile-associated disease due to the highly virulent clone of Clostridium difficile PCR ribotype 027, March 2007 in Germany. Euro Surveill 2007, I2(II):E07| II I.I.

19. van Belkum A, Tassios PT, Dijkshoorn L, Haegsman S, Cookson B, Fry NK, Fussing V, Green J, Feil E, Gerner-Smidt P, et al.: Guidelines for the validation and application of typing methods for use in bacterial epidemiology. Clin Microbiol Infect 2007, I3(Supp 3): $1-46$.

20. Berg RJ van den, Schaap I, Templeton $\mathrm{KE}$, Klaassen $\mathrm{CH}$, Kuijper EJ: Typing and subtyping of Clostridium difficile isolates by using multiple-locus variable-number tandem-repeat analysis. J Clin Microbiol 2007, 45(3): I024-1028.

2I. Marsh JW, O'Leary MM, Shutt KA, Pasculle AW, Johnson S, Gerding DN, Muto CA, Harrison LH: Multilocus variable-number tandem-repeat analysis for investigation of Clostridium difficile transmission in Hospitals. J Clin Microbiol 2006, 44(7):2558-2566.

22. Fawley WN, Freeman J, Smith C, Harmanus C, Berg RJ van den, Kuijper EJ, Wilcox $\mathrm{MH}$ : Use of highly discriminatory fingerprinting to analyze clusters of Clostridium difficile infection cases due to epidemic ribotype 027 strains. I Clin Microbiol 2008, 46(3):954-960.

23. Killgore G, Thompson A, Johnson S, Brazier J, Kuijper E, Pepin J, Frost EH, Savelkoul P, Nicholson B, Berg RJ van den, et al: Comparison of seven techniques for typing international epidemic strains of Clostridium difficile: restriction endonuclease analysis, pulsed-field gel electrophoresis, PCR-ribotyping, multilocus sequence typing, multilocus variable-number tandemrepeat analysis, amplified fragment length polymorphism, and surface layer protein A gene sequence typing. I Clin Microbiol 2008, 46(2):43I-437.

24. Gal M, Northey G, Brazier JS: A modified pulsed-field gel electrophoresis (PFGE) protocol for subtyping previously nonPFGE typeable isolates of Clostridium difficile polymerase chain reaction ribotype 00 I. J Hosp Infect 2005, 6 I (3):23I-236.
25. Stubbs SL, Brazier JS, O'Neill GL, Duerden BI: PCR targeted to the 16S-23S rRNA gene intergenic spacer region of Clostridium difficile and construction of a library consisting of I 16 different PCR ribotypes. J Clin Microbiol I999, 37(2):46|-463.

26. Bidet $P$, Barbut F, Lalande V, Burghoffer B, Petit JC: Development of a new PCR-ribotyping method for Clostridium difficile based on ribosomal RNA gene sequencing. FEMS Microbiol Lett 1999, 175(2):261-266

27. Bidet P, Lalande V, Salauze B, Burghoffer B, Avesani V, Delmee M, Rossier A, Barbut F, Petit JC: Comparison of PCR-ribotyping, arbitrarily primed PCR, and pulsed-field gel electrophoresis for typing Clostridium difficile. J Clin Microbiol 2000, 38(7):2484-2487.

28. Spigaglia P, Cardines R, Rossi S, Menozzi MG, Mastrantonio P: Molecular typing and long-term comparison of clostridium difficile strains by pulsed-field gel electrophoresis and PCR-ribotyping. J Med Microbiol 200I, 50(5):407-4I4

29. Brazier JS: The epidemiology and typing of Clostridium difficile. J Antimicrob Chemother 1998, 4 I (Suppl C):47-57.

30. Clabots CR, Johnson S, Bettin KM, Mathie PA, Mulligan ME, Schaberg $\mathrm{DR}$, Peterson LR, Gerding DN: Development of a rapid and efficient restriction endonuclease analysis typing system for Clostridium difficile and correlation with other typing systems. J Clin Microbiol 1993, 3 I(7): I870-1875.

3I. Lemee L, Dhalluin A, Pestel-Caron M, Lemeland JF, Pons JL: Multilocus sequence typing analysis of human and animal Clostridium difficile isolates of various toxigenic types. J Clin Microbiol 2004, 42(6):2609-26I7.

32. Lemee L, Bourgeois I, Ruffin E, Collignon A, Lemeland JF, Pons JL: Multilocus sequence analysis and comparative evolution of virulence-associated genes and housekeeping genes of Clostridium difficile. Microbiology 2005, I5 I (Pt | 0):3 I7I-3 I80.

33. Shopsin B, Gomez M, Montgomery SO, Smith DH, Waddington M, Dodge DE, Bost DA, Riehman M, Naidich S, Kreiswirth BN: Evaluation of protein $A$ gene polymorphic region DNA sequencing for typing of Staphylococcus aureus strains. J Clin Microbiol 1999, 37(II):3556-3563.

34. Meinersmann RJ, Helsel LO, Fields PI, Hiett KL: Discrimination of Campylobacter jejuni isolates by fla gene sequencing. J Clin Microbiol I 997, 35(I I):28।0-28।4

35. Price EP, Thiruvenkataswamy V, Mickan L, Unicomb L, Rios RE, Huygens F, Giffard PM: Genotyping of Campylobacter jejuni using seven single-nucleotide polymorphisms in combination with flaA short variable region sequencing. J Med Microbiol 2006, 55(Pt 8): $1061-1070$

36. Beall B, Facklam R, Thompson T: Sequencing emm-specific PCR products for routine and accurate typing of group $A$ streptococci. J Clin Microbiol 1996, 34(4):953-958.

37. Russell JE, Jolley KA, Feavers IM, Maiden MC, Suker J: PorA variable regions of Neisseria meningitidis. Emerg Infect Dis 2004, I0(4):674-678

38. Thompson EA, Feavers IM, Maiden MC: Antigenic diversity of meningococcal enterobactin receptor FetA, a vaccine component. Microbiology 2003, I49(Pt 7): |849-1858.

39. Elias J, Harmsen D, Claus H, Hellenbrand W, Frosch M, Vogel U: Spatiotemporal analysis of invasive meningococcal disease, Germany. Emerg Infect Dis 2006, I 2(I I): 1689-1695

40. Kato $H$, Yokoyama $T$, Arakawa $Y$ : Typing by sequencing the slpA gene of Clostridium difficile strains causing multiple outbreaks in Japan. J Med Microbiol 2005, 54(Pt 2): I67-I7|.

41. Sebaihia M, Wren BW, Mullany P, Fairweather NF, Minton N, Stabler $\mathrm{R}$, Thomson NR, Roberts AP, Cerdeno-Tarraga AM, Wang $\mathrm{H}$, et al: The multidrug-resistant human pathogen Clostridium difficile has a highly mobile, mosaic genome. Nat Genet 2006, 38(7):779-786

42. Benson G: Tandem repeats finder: a program to analyze DNA sequences. Nucleic Acids Res 1999, 27(2):573-580.

43. Levinson G, Gutman GA: Slipped-strand mispairing: a major mechanism for DNA sequence evolution. Mol Biol Evol 1987 , 4(3):203-221.

44. Schlotterer C: Evolutionary dynamics of microsatellite DNA. Chromosoma 2000, 109(6):365-37I.

45. Eisen J: Mechanistic basis for microsatellite instability. In Microsatellites: evolution and applications Edited by: Goldstein DB, Schötterer C. Oxford University Press, New York, NY; 1999:34-48. 
46. Nübel U, Roumagnac $P$, Feldkamp M, Song J-H, Ko KS, Huang Y-C, Coombs G, Ip M, Skov R, Strommenger B, et al.: Frequent emergence and limited geographic dispersal of methicillin-resistant Staphylococcus aureus. Proc Nat Acad Sci USA 2008, 105:14130-14135.

47. Benson G: Sequence alignment with tandem duplication. J Comput Biol 1997, 4(3):35I-367.

48. Hunter PR, Gaston MA: Numerical index of the discriminatory ability of typing systems: an application of Simpson's index of diversity. J Clin Microbiol 1988, 26( I I):2465-2466.

49. Grundmann H, Hori S, Tanner G: Determining confidence intervals when measuring genetic diversity and the discriminatory abilities of typing methods for microorganisms. J Clin Microbiol 200I, 39(II):4190-4192.

50. Carrico JA, Silva-Costa C, Melo-Cristino J, Pinto FR, de Lencastre H, Almeida JS, Ramirez M: Illustration of a common framework for relating multiple typing methods by application to macrolide-resistant Streptococcus pyogenes. J Clin Microbiol 2006, 44(7):2524-2532.

5I. Nei M, Gojobori T: Simple methods for estimating the numbers of synonymous and nonsynonymous nucleotide substitutions. Mol Biol Evol 1986, 3(5):418-426.

Publish with Bio Med Central and every scientist can read your work free of charge

"BioMed Central will be the most significant development for disseminating the results of biomedical research in our lifetime. "

Sir Paul Nurse, Cancer Research UK

Your research papers will be:

- available free of charge to the entire biomedical community

- peer reviewed and published immediately upon acceptance

- cited in PubMed and archived on PubMed Central

- yours - you keep the copyright

Submit your manuscript here:

http://www.biomedcentral.com/info/publishing_adv.asp
BiolMedcentral 